\title{
Polyglycerol-functionalized nanodiamond as a platform for gene delivery: Derivatization, characterization, and hybridization with DNA
}

\author{
Li Zhao', Yuki Nakae ${ }^{2}$, Hongmei Qin ${ }^{1}$, Tadamasa Ito ${ }^{3}$, Takahide Kimura ${ }^{1}$, \\ Hideto Kojima ${ }^{2}$, Lawrence Chan ${ }^{4}$ and Naoki Komatsu ${ }^{* 1, \S}$
}

\section{Full Research Paper}

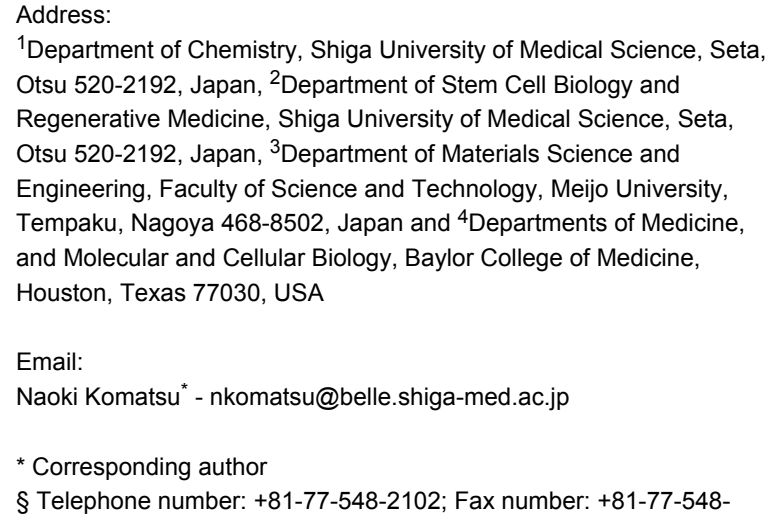

${ }^{1}$ Department of Chemistry, Shiga University of Medical Science, Seta, Otsu 520-2192, Japan, ${ }^{2}$ Department of Stem Cell Biology and Regenerative Medicine, Shiga University of Medical Science, Seta, Otsu 520-2192, Japan, ${ }^{3}$ Department of Materials Science and Engineering, Faculty of Science and Technology, Meijo University, Tempaku, Nagoya 468-8502, Japan and ${ }^{4}$ Departments of Medicine, and Molecular and Cellular Biology, Baylor College of Medicine, Houston, Texas 77030, USA

Email:

Naoki Komatsu ${ }^{*}$ - nkomatsu@belle.shiga-med.ac.jp

* Corresponding author

$\S$ Telephone number: +81-77-548-2102; Fax number: +81-77-5482405

\section{Keywords:}

carbon-nanomaterials; click chemistry; DNA; gene delivery;

nanodiamond; polyglycerol; polypeptides
Beilstein J. Org. Chem. 2014, 10, 707-713.

doi:10.3762/bjoc.10.64

Received: 12 October 2013

Accepted: 04 March 2014

Published: 24 March 2014

This article is part of the Thematic Series "Functionalized carbon-nanomaterials".

Guest Editor: A. Krueger

(c) 2014 Zhao et al; licensee Beilstein-Institut. License and terms: see end of document.

\begin{abstract}
A gene vector consisting of nanodiamond, polyglycerol, and basic polypeptide (ND-PG-BPP) has been designed, synthesized, and characterized. The ND-PG-BPP was synthesized by PG functionalization of ND through ring-opening polymerization of glycidol on the ND surface, multistep organic transformations ( $-\mathrm{OH} \rightarrow-\mathrm{OTs}$ (tosylate) $\rightarrow-\mathrm{N}_{3}$ ) in the PG layer, and click conjugation of the basic polypeptides ( $\mathrm{Arg}_{8}, \mathrm{Lys}_{8}$ or $\mathrm{His}_{8}$ ) terminated with propargyl glycine. The ND-PG-BPP exhibited good dispersibility in water $(>1.0 \mathrm{mg} / \mathrm{mL})$ and positive zeta potential ranging from $+14.2 \mathrm{mV}$ to $+44.1 \mathrm{mV}$ at neutral $\mathrm{pH}$ in Milli-Q water. It was confirmed by gel retardation assay that ND-PG-Arg 8 and ND-PG-Lys 8 with higher zeta potential hybridized with plasmid DNA (pDNA) through electrostatic attraction, making them promising as nonviral vectors for gene delivery.
\end{abstract}

\section{Introduction}

A variety of nanoparticles have been investigated as nonviral vectors in drug and gene delivery systems [1,2]. Among these nanoparticles, nanodiamond (ND) has attracted a great deal of attention due to its high chemical stability, low toxicity, and large specific surface area [3-6]. In addition, various functions can be added to ND through organic reactions on the ND 
surface [4,5,7-11]. In this sense, ND has an advantage over noncarbonaceous nanomaterials, because the methodology in synthetic organic chemistry can be applied to the ND surface, which is covered with organic functional groups [12]. Quite recently, we found that ring-opening polymerization of glycidol is initiated at the oxygen-containing functionalities, hydroxy and carboxy groups, on the ND surface to give polyglycerol(PG) grafted ND with $30 \mathrm{~nm}$ size (ND30-PG) [13]. The resulting ND30-PG exhibited very good dispersibility not only in water $(>20 \mathrm{mg} / \mathrm{mL})$, but also in phosphate buffererd saline (PBS) $(>16 \mathrm{mg} / \mathrm{mL})$, making the in vivo use of ND more promising in biomedical applications. In addition, the good dispersibility and a large number of hydroxy groups of ND-PG enable further surface functionalization to add more functions to ND [14].

As for gene delivery, on the other hand, DNA was immobilized on the surface of nanoparticles mostly by electrostatic attraction between the negative charge of DNA and the positive charge on the surface of the nanoparticle [15]. In the case of ND, for example, basic polypeptides [16], polyamine polymer [17], primary and tertiary amines [17,18], and quaternary ammonium salts [19] were employed to coat ND covalently or noncovalently as positively charged ligands for DNA immobilization. Although the functionalized ND is proven to immobilize DNA, more functions such as enough dispersibility and targeting efficacy are required to use ND in vivo as a gene vector. Therefore, a more reliable and general process is desired to add sufficient functions for ND-based gene vectors. Herein a conjugation of ND-PG with basic polypeptides $\left(\mathrm{Arg}_{8}, \mathrm{Lys}_{8}\right.$ and $\mathrm{His}_{8}$ ) through click chemistry followed by hybridization with plasmid DNA (pDNA) and its characterization by electrophoresis is reported.

\section{Results and Discussion \\ Preparation and characterization of ND50-PG} In view of actual cancer therapy utilizing the enhanced permeation and retention (EPR) effect, ND with $50 \mathrm{~nm}$ size was chosen for this study. The ND50 was covalently functionalized with hyperbranched PG through ring-opening polymerization of glycidol according to the procedure we reported previously [13]. The resulting ND50-PG was characterized qualitatively by FTIR and ${ }^{1} \mathrm{H}$ NMR, and quantitatively by TGA. The IR (Figure 1a) and NMR spectra (Figure 2a) of ND50-PG are almost the same as those of ND30-PG [13], proving the PG grafting on the ND50. In addition, PG:ND weight ratio of ND50-PG (37:63) is almost the same as that of ND30-PG (40:60) in TGA (Figure 3), though ND50 has a smaller specific surface area than ND30. Accordingly, the dispersibility $(>20 \mathrm{mg} / \mathrm{mL})$ of ND50-PG in water is almost the same as that of ND30-PG [13]. However, ND5-PG showed an opposite weight ratio (PG:ND = 78:22), though IR and NMR spectra

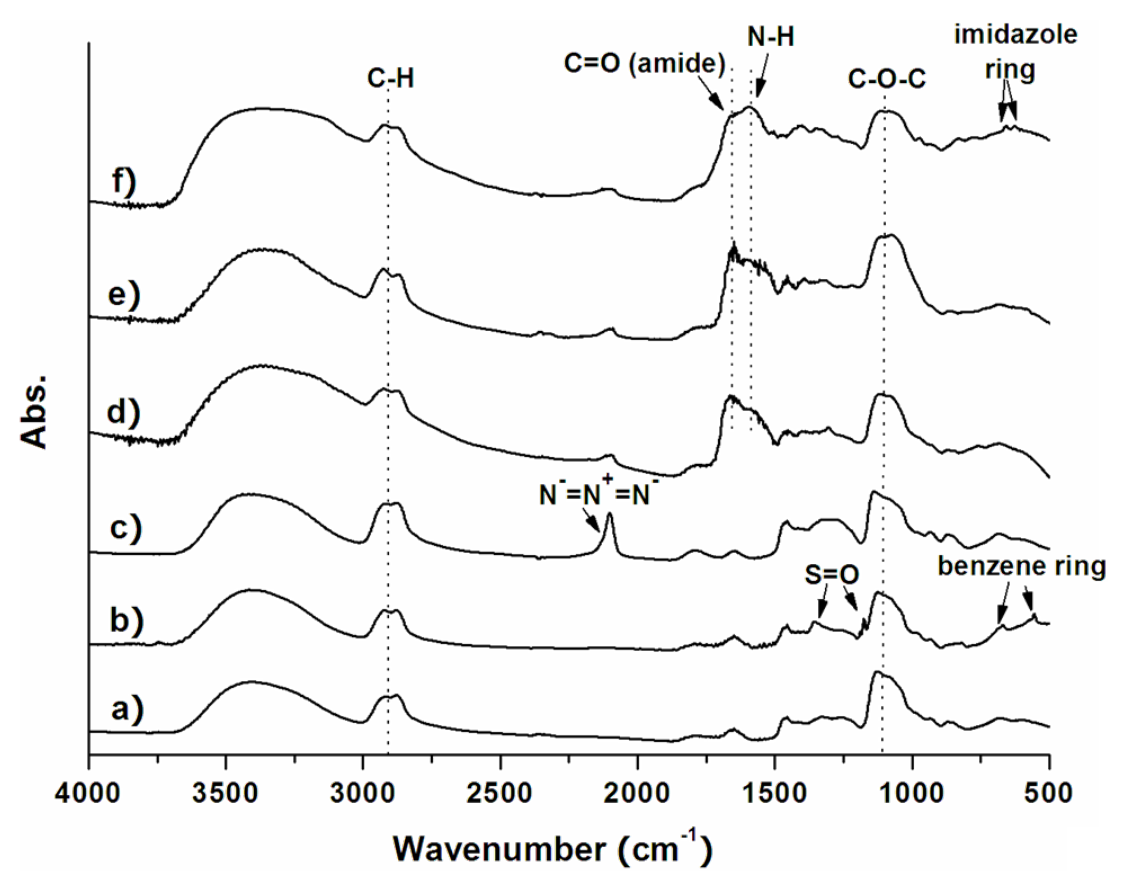

Figure 1: FTIR spectra of a) ND50-PG, b) ND-PG-OTs, c) ND-PG-N 3 , d) ND-PG-Arg8, e) ND-PG-Lys 8 , and f) ND-PG-His 8 . Arrows indicate new absorption bands in each step. 


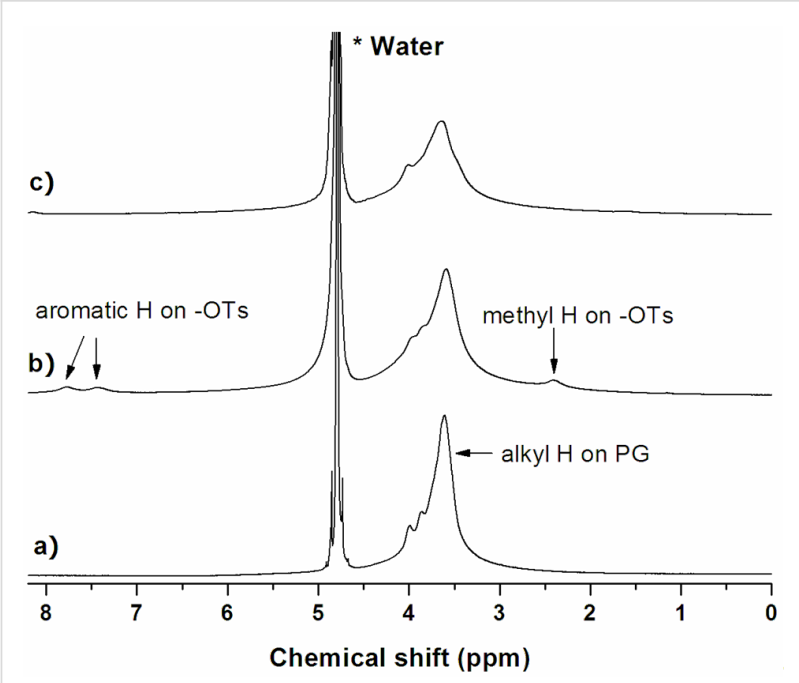

Figure 2: ${ }^{1} \mathrm{H}$ NMR spectra of a) ND50-PG, b) ND-PG-OTs and c) ND-PG- $\mathrm{N}_{3}$ in $\mathrm{D}_{2} \mathrm{O}$.

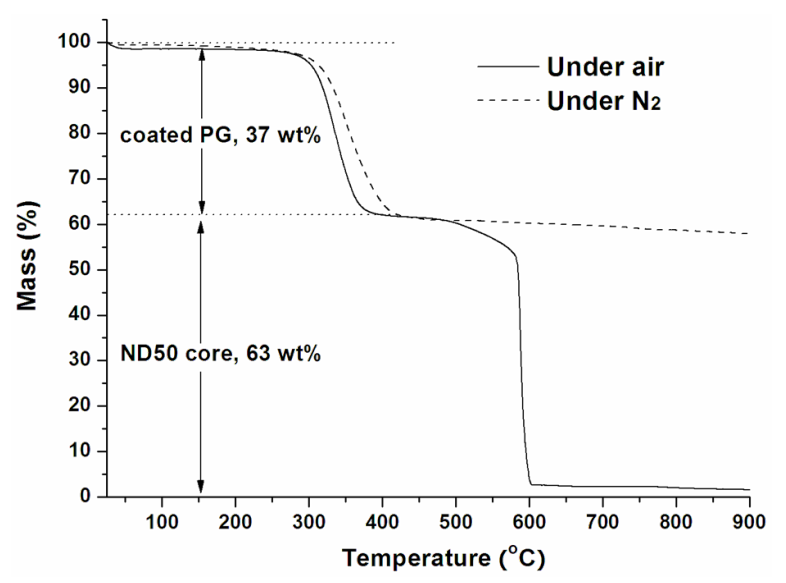

Figure 3: TGA profiles of ND50-PG under nitrogen and air. were almost the same as those of ND30-PG and ND50-PG [20]. The much larger weight ratio of the PG layer improved the dispersibility of ND5-PG significantly ( $>80 \mathrm{mg} / \mathrm{mL}$ in PBS), implying that the dispersibility of ND-PG is proportional to the weight ratio of PG to the ND core.

The particle size of ND50 and ND50-PG was measured by STEM and DLS. In contrast to bare ND50 particles that are prone to aggregate (Figure 4a), ND50-PG is individually dispersed as shown in Figure 4b. Moreover, 5-10 nm blank space between the ND particles in the STEM image (Figure 4b) may be attributed to the PG layer on the ND surfaces. The average core diameter and the mean hydrodynamic diameter of ND50-PG were determined to be $52.2 \pm 14.4 \mathrm{~nm}$ by STEM (Figure $4 \mathrm{~b}$ ) and $66.9 \pm 14.8 \mathrm{~nm}$ by DLS (Table 1), respectively. Based on the difference of the core and hydrodynamic diameters, the thickness of the PG layer on the ND50-PG was estimated to be ca. $7 \mathrm{~nm}$, which is in agreement with the interparticle distance in the STEM image (Figure 4b) as mentioned above.

Table 1: Hydrodynamic diameter and zeta potential of nanoparticles in Milli-Q water.

\begin{tabular}{ccc} 
Nanoparticle & $\begin{array}{c}\text { Hydrodynamic } \\
\text { diameter }^{\mathrm{a}}(\mathrm{nm})\end{array}$ & $\begin{array}{c}\text { Zeta potential } \\
(\mathrm{mV})\end{array}$ \\
\hline ND50 & $52.8 \pm 20.3$ & $-46.7 \pm 3.5$ \\
ND50-PG & $66.9 \pm 14.8$ & $-36.8 \pm 1.7$ \\
ND-PG-Arg & $372 \pm 105$ & $+44.1 \pm 1.9$ \\
ND-PG-Lys 8 & $176 \pm 44$ & $+38.7 \pm 1.4$ \\
ND-PG-His 8 & $195 \pm 64$ & $+14.2 \pm 0.5$ \\
\hline
\end{tabular}

aMean diameter \pm SD was determined by DLS on the basis of number distribution.
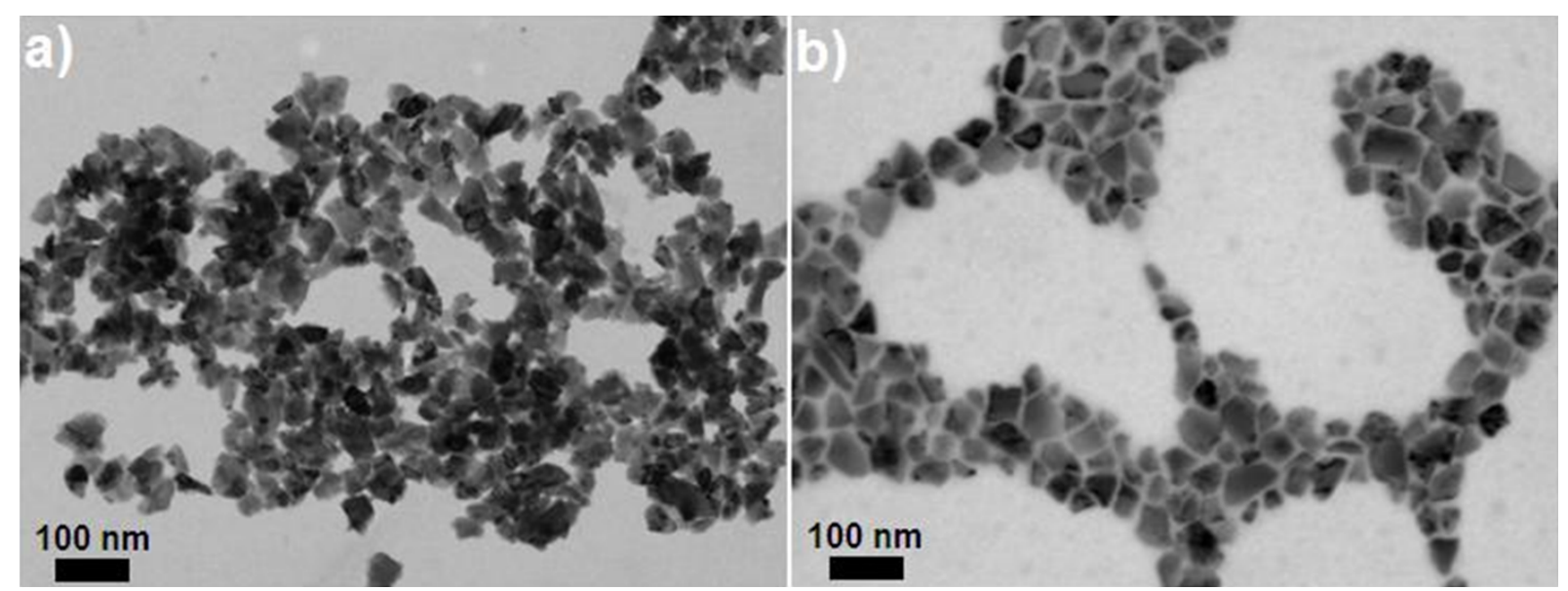

Figure 4: STEM images of a) pristine ND50 and b) ND50-PG. 


\section{Immobilization of basic polypeptides through click chemistry}

The PG layer including a large number of hydroxy groups endows ND50-PG not only with very high hydrophilicity (Figure 5), but also with a versatile platform for further surface engineering. The synthetic route from ND50-PG to ND-PGBPP is shown in Scheme 1. Some of the hydroxy groups of ND50-PG were reacted with tosyl chloride $(\mathrm{TsCl})$ in pyridine and the resulting tosylates (ND-PG-OTs) were substituted by azide (ND-PG-N 3 ). The azido groups reacted with the alkyne group at the end of the polypeptides (click chemistry) to produce ND-PG-BPP [12,21,22].

A series of reactions from ND-PG to ND-PG-BPP were monitored by FTIR (Figure 1) [20]. The absorption bands at $1350 \mathrm{~cm}^{-1}$ and $1176 \mathrm{~cm}^{-1}$ are attributed to asymmetric and symmetric stretchings of $\mathrm{S} \rightarrow \mathrm{O}$ bonds of the tosyl group in ND-PG-OTs, respectively. Another two new absorption bands at 556 and $669 \mathrm{~cm}^{-1}$ are assigned to the bending vibrations of aromatic $\mathrm{C}-\mathrm{H}$ (Figure 1b). The ND-PG-N 3 clearly shows a characteristic strong absorption band at $2100 \mathrm{~cm}^{-1}$ corresponding to the azido group (Figure 1c). The azido absorption band disappeared after the click conjugation of the BPP (Figure 1d-f), indicating the complete consumption of azido groups. The immobilization of polypeptides was verified by the absorption bands at 1650 and $1590 \mathrm{~cm}^{-1}$, which correspond to the $\mathrm{C}=\mathrm{O}$ stretching and $\mathrm{N}-\mathrm{H}$ bending of amide bonds in the polypeptide. In the case of ND-PG-His 8 , absorption peaks at 624 and $657 \mathrm{~cm}^{-1}$ are attributed to $\mathrm{C}-\mathrm{H}$ bending of the imidazole rings in the polyhistidine (Figure 1f).
Taking advantage of the good dispersibility of the ND50-PG and their derivatives, they are characterized by solution-phase ${ }^{1} \mathrm{H}$ NMR (Figure 2). As shown in Figure 2b, the peaks at 7.7 and $7.4 \mathrm{ppm}$ are assigned to the aromatic hydrogens of the tosyl group, and the methyl hydrogens are found at $2.3 \mathrm{ppm}$. These three peaks of the ND-PG-OTs in Figure $2 b$ disappeared in Figure $2 \mathrm{c}$ after the reaction with sodium azide, indicating the complete substitution of the tosyl group.

The hydrodynamic diameter of ND-PG-BPP in water largely increased to more than $150 \mathrm{~nm}$ (Table 1), indicating that aggregation occurred in the dispersions. Since ND-PG-BPP has positive charge as will be discussed below, the charges may be connected by some anions to assemble the particles. However, ND-PG-BPP still has dispersibility of $>1.0 \mathrm{mg} / \mathrm{mL}$ with less stability (Figure 5).

\section{Zeta potential characterization and pDNA complexation}

To analyze the surface charge of the nanoparticles, we measured the zeta potential of ND50, ND50-PG and ND-PG$\mathrm{BPP}$ at neutral $\mathrm{pH}$ in Milli-Q water. The results are summarized in Table 1. ND50 showed a relatively high negative zeta potential of $-46.7 \pm 3.5 \mathrm{mV}$ because of a large number of carboxylic groups on the surface. The zeta potential changed to $-36.8 \pm 1.7 \mathrm{mV}$ by PG coating of ND50, probably because some of the carboxylic groups (protic functional groups) are converted to ester (aprotic ones) by initiation of the ringopening polymerization of glycidol. The immobilization of polypeptides turned the zeta potentials into plus $(-36.8 \mathrm{mV} \rightarrow$

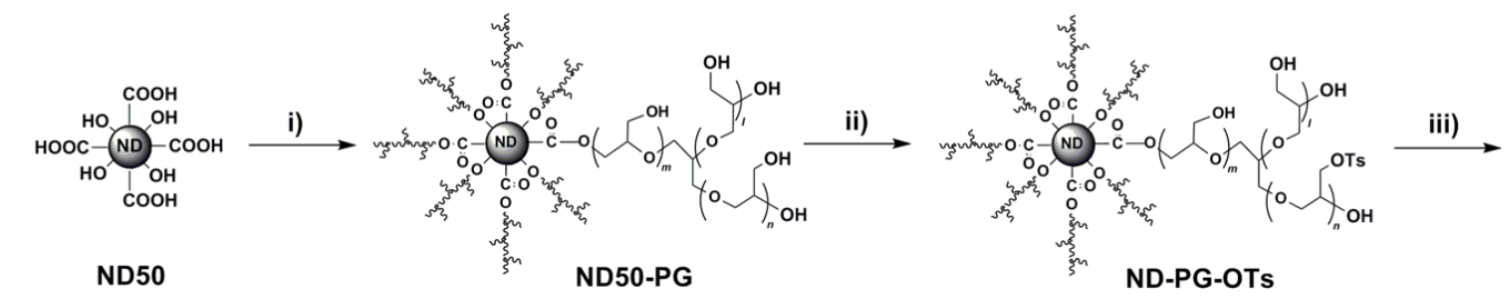

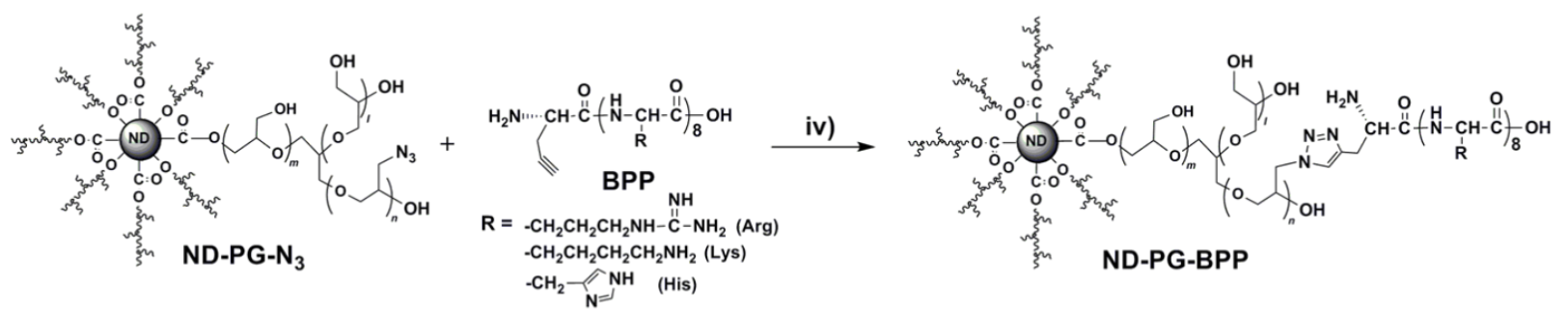




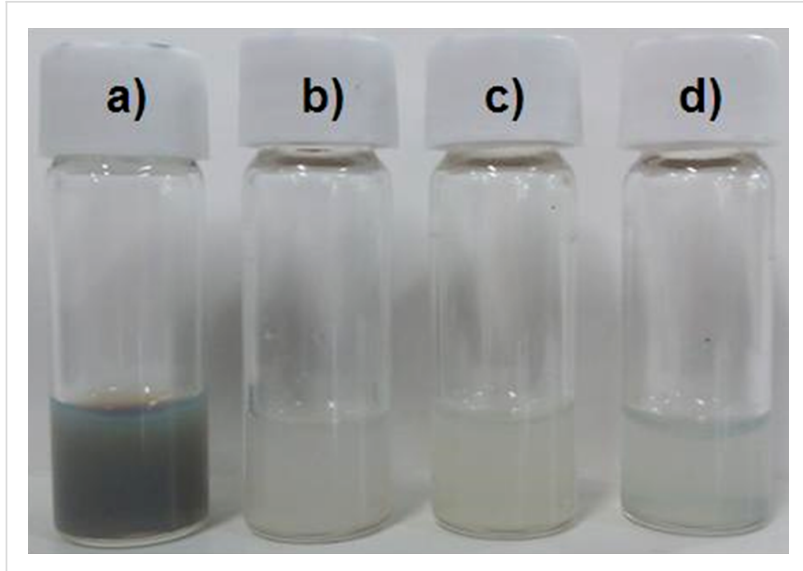

Figure 5: Picture of the dispersions of a) ND50-PG $(20 \mathrm{mg} / \mathrm{mL})$, b) ND-PG-Arg 8 , c) ND-PG-Lys 8 and d) ND-PG-His $(\mathrm{b}-\mathrm{d}, 1.0 \mathrm{mg} / \mathrm{mL}$ ) in water.

+14.2 to $+44.1 \mathrm{mV}$ ) due to the protonation to the basic groups in the peptides; imidazole, amine, and guanidine. These zeta potentials of the ND-PG-BPP are roughly propotional to the $\mathrm{p} K \mathrm{a}$ values of the side chains in these basic amino acids; His (6.0), Lys (10.5), and Arg (12.5).

The positive surface charge of nanoparticles enables complexation with negatively charged DNA through electrostatic interaction. To analyze the DNA complexation capability of the ND-PG-BPP, we performed an agarose gel retardation assay. The result of the electrophoresis is shown in Figure 6. ND-PG$\mathrm{Arg}_{8}$ and ND-PG-Lys 8 with higher positive zeta potential formed complexes with the pDNA, which can be seen as becoming light of density of the pDNA bands. In particular, ND-PG-Arg 8 with the highest positive zeta potential completely retarded the pDNA at a low NP:pDNA weight ratio (30:1). In contrast, ND50-PG and ND-PG-His 8 were not able to form a complex with the pDNA even at the highest NP:pDNA weight ratio $(50: 1)$.

\section{Conclusion}

We have prepared ND-PG-BPP through multistep organic transformations including click chemistry. The PG layer on ND gave good aqueous dispersibility, enabling derivatization and characterization in the solution phase. The ND-PG-Arg 8 and ND-PG-Lys 8 possessing relatively high positive zeta potential immobilized the pDNA, demonstrating their potential of ND-PG-BPP as vectors for gene delivery.

\section{Experimental}

\section{Materials and instruments}

All the reagents and solvents used for the synthesis were employed as received. ND with $50 \mathrm{~nm}$ median diameter (ND50), prepared from high-pressure-high-temperature (HPHT)

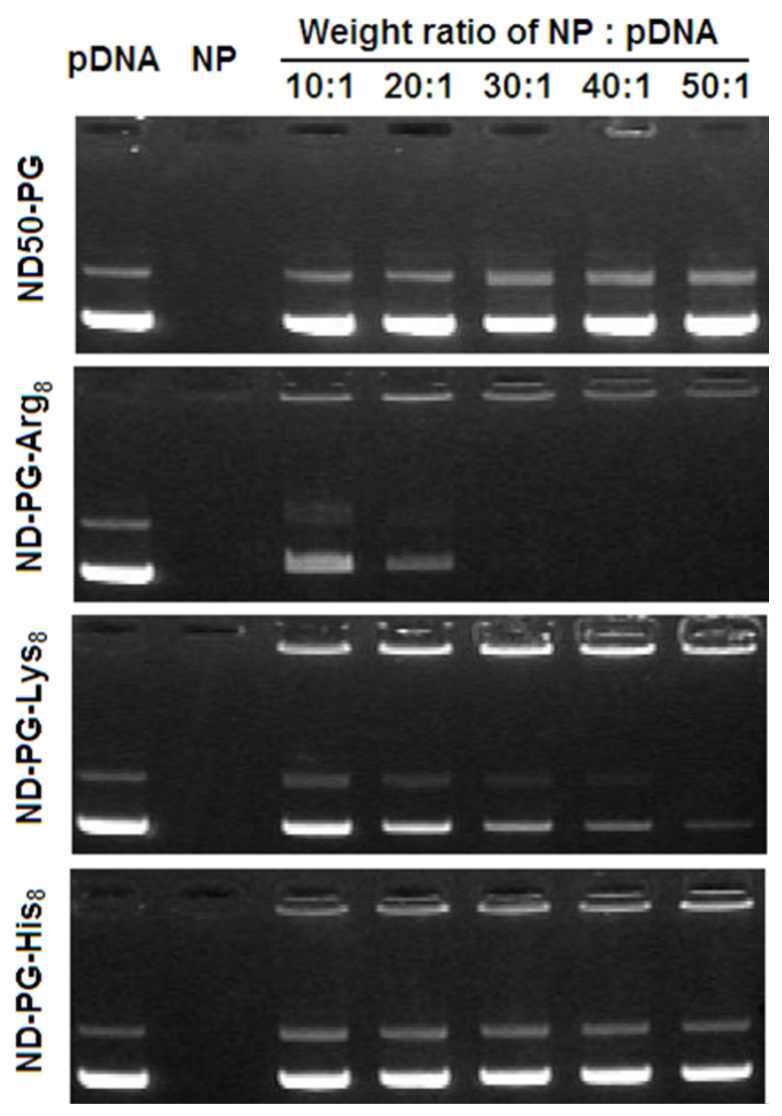

Figure 6: Electrophoretic migration of pDNA, NP (ND50-PG or ND-PG-BPP), and NP/pDNA mixtures at various weight ratios.

bulk diamond, was kindly provided by Tomei Diamond Co., Ltd. (Lot. No. 66093). Glycidol was purchased from Kanto Chemical Co., Ltd. $p$-Toluenesulfonyl chloride and sodium azide were purchased from Nacalai Tesque, Co. Basic polypeptides binding propargyl glycine $\left(\mathrm{G}^{*}\right)$ at an $\mathrm{N}$ terminal $\left(\mathrm{G}^{*} \mathrm{BPP}\right)$ were obtained from two sources; $\mathrm{G}^{*} \mathrm{Lys}_{8}$ and $\mathrm{G}^{*} \mathrm{His}_{8}$ were synthesized by the central research laboratory of Shiga University of Medical Science and $\mathrm{G}^{*} \mathrm{Arg}_{8}$ was purchased from GL Biochem Ltd. in Shanghai, China. The pBluescript II KS (Agilent Technologies, Inc., Tokyo, Japan) was used as a test pDNA for the hybridization with ND-PG-BPP. Dialysis was carried out by use of Spectra/Pro ${ }^{\circledR}$ dialysis membrane, MWCO: $12-14 \mathrm{kDa}$.

FTIR spectral measurements were conducted using IR Prestige21 (Shimadzu Co.). Samples were prepared by drop-coating of suspension to form a thin film on a stainless alloy plate, and then dried at $70{ }^{\circ} \mathrm{C}$. Hydrodynamic diameters in solution were determined by dynamic light scattering (DLS) using a Nanotrac UPA-UT151 system (Microtrac, Inc.). ${ }^{1} \mathrm{H}$ NMR spectra (270 MHz) were recorded on a JEOL Model JNM-EX270 spec- 
trometer. Scanning transmission electron microscopy (STEM) was performed on a JEOL JSM-7500F field emission scanning electron microscope at $25 \mathrm{kV}$ accelerating voltage for the TEM model. All samples for electron microscopy were prepared by evaporating one drop $(\sim 50 \mu \mathrm{L})$ of samples on ultrathin carboncoated copper grids. Thermogravimetric analyses (TGA) were carried out by a Q-50 analyzer (TA instruments) with a heating rate of $20^{\circ} \mathrm{C} / \mathrm{min}$ under a nitrogen or an air flow $(60 \mathrm{~mL} / \mathrm{min})$. Zeta potential measurement was conducted in water solutions using an Otsuka ELSZ-1 zeta-potential analyzer.

\section{Synthesis and characterization ND50-PG}

ND50-PG was prepared according to our reported method [13] using ND50 as a starting material, and characterized by FTIR (Figure 1a) and solution-phase ${ }^{1} \mathrm{H}$ NMR (Figure 2a).

\section{ND-PG-OTs}

ND50-PG $(100 \mathrm{mg})$ was dissolved in pyridine $(4.0 \mathrm{~mL})$ by bath sonication and then cooled down to $0{ }^{\circ} \mathrm{C}$ in an ice/water bath. $p$-Toluenesulfonyl chloride (200 mg, $1.05 \mathrm{mmol})$ was dissolved in pyridine $(2.0 \mathrm{~mL})$ and added dropwise into the mixture under rapid stirring. The solution was stirred at $0-5{ }^{\circ} \mathrm{C}$ for $3 \mathrm{~h}$ and at room temperature overnight. The resulting solid was collected by centrifugation (Beckman Coulter Avanti ${ }^{\circledR} \mathrm{J}$-E centrifuge) at $50400 \mathrm{~g}$ and purified in DMF by repeated redispersion/centrifugation cycles. It was characterized by FTIR (Figure 1b) and solution-phase ${ }^{1} \mathrm{H}$ NMR (Figure $2 \mathrm{~b}$ ).

\section{ND-PG-N 3}

In a similar manner to our reported method [20], sodium azide $(100 \mathrm{mg}, 1.54 \mathrm{mmol})$ in water $(2.0 \mathrm{~mL})$ was added into ND-PGOTs $(80 \mathrm{mg})$ in DMF $(6.0 \mathrm{~mL})$ and stirred at $90^{\circ} \mathrm{C}$ overnight. After cooling down, the product was collected by centrifugation and purified in water by repeated redispersion/centrifugation cycles. It was characterized by FTIR (Figure 1c) and solution-phase ${ }^{1} \mathrm{H}$ NMR (Figure 2c).

\section{ND-PG-BPP}

The click reaction of ND-PG-N $\mathrm{N}_{3}$ and $\mathrm{G}^{*} \mathrm{BPP}$ was conducted in a similar manner to our reported procedure [22]. G*BPP $(8.0 \mathrm{mg})$ was added to a solution of ND-PG-N $3(10 \mathrm{mg})$ in water $(2.0 \mathrm{~mL})$. Copper(II) sulfate pentahydrate $(8.0 \mathrm{mg})$ in water $(0.5 \mathrm{~mL})$ and sodium ascorbate $(10 \mathrm{mg})$ in water $(0.5 \mathrm{~mL})$ were added into the mixture with vigorous stirring. The resulting brown suspension was bath-sonicated for $10 \mathrm{~min}$ and then stirred at room temperature for $96 \mathrm{~h}$. Diluted ammonia was dropped into the suspension to dissolve insoluble copper salts, giving a blue-gray suspension. The solid was collected by centrifugation and washed with $1 \%$ ammonia repeatedly. The washed sample was dialyzed against Milli-Q water to thor- oughly remove ammonia. The resulting ND-PG-BPP were characterized by FTIR (Figure 1d-f). Decent NMR spectra of the ND-PG-BPP were not obtained because of lower dispersibility of the ND-PG-BPP than the above ND-PG derivatives.

\section{Gel retardation assay}

The hybridization of ND-PG-BPP with DNA was studied by means of an agarose gel retardation assay. The agarose gel was prepared by dissolving $1 \%(\mathrm{w} / \mathrm{v})$ agarose in tris-acetate-EDTA (TAE) buffer containing ethidium bromide $(0.1 \mathrm{mg} / \mathrm{mL})$. The ND-PG-BPP was mixed with $0.2 \mu \mathrm{g}$ of pDNA in $10 \mu \mathrm{L}$ doubledistilled water at designated NP (ND-PG-BPP):pDNA weight ratios (Figure 6). The mixture together with ND-PG-BPP and pDNA were loaded into the slots of the gel and subjected to electrophoresis at a voltage of $100 \mathrm{~V}$ for $20 \mathrm{~min}$. The pDNA in the gel was visualized and photographed on a FAS-IV ultraviolet transilluminator (Nippon Genetics Co. Ltd).

\section{Acknowledgements}

This work was financially supported by the Science and Technology Incubation Program in Advanced Region (JST), Industrial Technology Research Grant Program (NEDO), Grant-inAid for Challenging Exploratory Research (JSPS), and Hoansha Fundation (to H. K.). The authors thank Dr. Nobuhiro Ogawa (Shiga University of Medical Science) and Tomei Diamond Co., Ltd. for providing us with pDNA and ND50, respectively. We are also grateful to Prof. Masaki Ozawa (Meijo University) for zeta potential measurements.

\section{References}

1. Mintzer, M. A.; Simanek, E. E. Chem. Rev. 2009, 109, 259-302. doi:10.1021/cr800409e

2. Guo, X.; Huang, L. Acc. Chem. Res. 2012, 45, 971-979. doi:10.1021/ar200151m

3. Mochalin, V. N.; Shenderova, O.; Ho, D.; Gogotsi, Y. Nat. Nanotechnol. 2012, 7, 11-23. doi:10.1038/nnano.2011.209

4. Krueger, A. Chem.-Eur. J. 2008, 14, 1382-1390. doi:10.1002/chem.200700987

5. Krueger, A. Adv. Mater. 2008, 20, 2445-2449. doi:10.1002/adma.200701856

6. Krueger, A. J. Mater. Chem. 2011, 21, 12571-12578. doi:10.1039/c1jm11674f

7. Krueger, A.; Ozawa, M.; Jarre, G.; Liang, Y.; Stegk, J.; Lu, L. Phys. Status Solidi A 2007, 204, 2881-2887. doi:10.1002/pssa.200776330

8. Krüger, A.; Liang, Y.; Jarre, G.; Stegk, J. J. Mater. Chem. 2006, 16, 2322-2328. doi:10.1039/b601325b

9. Hartmann, M.; Betz, P.; Sun, Y.; Gorb, S. N.; Lindhorst, T. K.; Krueger, A. Chem.-Eur. J. 2012, 18, 6485-6492. doi:10.1002/chem.201104069

10. Takimoto, T.; Chano, T.; Shimizu, S.; Okabe, H.; Ito, M.; Morita, M.; Kimura, T.; Inubushi, T.; Komatsu, N. Chem. Mater. 2010, 22, 3462-3471. doi:10.1021/cm100566v 
11. Nakamura, T.; Ohana, T.; Yabuno, H.; Kasai, R.; Suzuki, T.; Hasebe, T. Appl. Phys. Express 2013, 6, 015001. doi:10.7567/APEX.6.015001

12. Krueger, A.; Lang, D. Adv. Funct. Mater. 2012, 22, 890-906. doi:10.1002/adfm.201102670

13. Zhao, L.; Takimoto, T.; Ito, M.; Kitagawa, N.; Kimura, T.; Komatsu, N. Angew. Chem., Int. Ed. 2011, 50, 1388-1392. doi:10.1002/anie.201006310

14. Calderón, M.; Quadir, M. A.; Sharma, S. K.; Haag, R. Adv. Mater. 2010, 22, 190-218. doi:10.1002/adma.200902144

15. Maeda-Mamiya, R.; Noiri, E.; Isobe, H.; Nakanishi, W.; Okamoto, K.; Doi, K.; Sugaya, T.; Izumi, T.; Homma, T.; Nakamura, E. Proc. Natl. Acad. Sci. U. S. A. 2010, 107, 5339-5344. doi:10.1073/pnas.0909223107

16. Kong, X.; Huang, L. C. L.; Liau, S.-C. V.; Han, C.-C.; Chang, H.-C. Anal. Chem. 2005, 77, 4273-4277. doi:10.1021/ac050213c

17. Zhang, X.-Q.; Chen, M.; Lam, R.; Xu, X.; Osawa, E.; Ho, D. ACS Nano 2009, 3, 2609-2616. doi:10.1021/nn900865g

18. Zhang, P.; Yang, J.; Li, W.; Wang, W.; Liu, C.; Griffith, M.; Liu, W. J. Mater. Chem. 2011, 21, 7755-7764. doi:10.1039/c1jm10813a

19. Martín, R.; Álvaro, M.; Herance, J. R.; García, H. ACS Nano 2010, 4, 65-74. doi:10.1021/nn901616c

20. Zhao, L.; Shiino, A.; Qin, H.; Kimura, T.; Komatsu, N. J. Nanosci. Nanotechnol., in press.

21. Meinhardt, T.; Lang, D.; Dill, H.; Krueger, A. Adv. Funct. Mater. 2011, 21, 494-500. doi:10.1002/adfm.201001219

22. Zhao, L.; Chano, T.; Morikawa, S.; Saito, Y.; Shiino, A.; Shimizu, S.; Maeda, T.; Irie, T.; Aonuma, S.; Okabe, H.; Kimura, T.; Inubushi, T.; Komatsu, N. Adv. Funct. Mater. 2012, 22, 5107-5117. doi:10.1002/adfm.201201060

\section{License and Terms}

This is an Open Access article under the terms of the Creative Commons Attribution License (http://creativecommons.org/licenses/by/2.0), which permits unrestricted use, distribution, and reproduction in any medium, provided the original work is properly cited.

The license is subject to the Beilstein Journal of Organic Chemistry terms and conditions:

(http://www.beilstein-journals.org/bjoc)

The definitive version of this article is the electronic one which can be found at: doi:10.3762/bjoc. 10.64 